\section{AL-AZHAR}

Assiut Dental Journal
The Official Publication of The

Faculty of Dental medicine.

Al-Azhar Assiut Uniuersity.

Egypt

AADJ, Vol. 2, No. 1, APRIL (2019) - PP. 31:39

ISSn 2682-2822

\title{
The Effect of Piezosurgical Ridge Splitting and Osseodensification on The Primary Stability of The Implant in Narrow Ridge: (Comparative Randomized Controlled Split Mouth Clinical Trial)
}

\author{
Elzahraa Abrahim Elgrany"1, Ibrahium Mahmoud Mwafey², Fathey Abdel Azium Abo Zaid ${ }^{2}$, \\ Khalid Seddik Hassan ${ }^{2}$
}

Codex : 04/1901

Aadj@azhar.edu.eg

\section{KEYWORDS}

Osseodensification, Piezosurgery, Ridge Splitting, Implant, Stability

1. Department of Oral Medicine, Periodontology and Diagnosis, Faculty of dentisty, Assiut University.

2. Department of Oral Medicine, Periodontology, Diagnosis and Oral Radiology, Faculty of Dentistry, Al-Azhar University, Assiut

* Corresponding author e-mail: Elzahraabrhim.19@azhar.edu.eg

\section{ABSTRACT}

Aim: This study aims to evaluate the effect of and compare between the piezosurgical ridge splitting and osseodensification in implant primary stability. Subjects and Methods: 28 implants were divided into two groups. Group I: 14 implants in sites received piezosurgery technique. Group II: 14 implants in sites received osseodensification technique. Then, all implants were evaluated clinically for primary stability after implant insertion by Osstell mentor magnetic resonance device and radiographically for peri-implant bone density. Results: unpaired t-test between the two groups showed moderate statistical significant difference in group II when compared with group I in both primary stability and bone density Conclusion: The primary stability in both piezosurgical ridge splitting and osseodensification techniques is within normal range but in favor of osseodensification technique suggesting that osseodensification enhance the bone density thereby improve the implant primary stability.

\section{INTRODUCTION}

Atrophic maxilla or mandible can lead to lack of prosthesis retention because of an inadequate bearing area causing both functional and physiological problems for patient, these problems can be treated for patient satisfaction with an implant supported fixed or removable complete or partial denture. Atrophic edentulous jaws can represent a significant challenge to the successful use of endosseous implants for prosthetic reconstruction of the edentulous mandible ${ }^{1,2}$.

Because an 8-mm-thick ridge is preferable for implant placement ${ }^{3}$, the resorption that happens after tooth extraction can lead to a ridge approximately $4.1 \mathrm{~mm}$ thick, which is not adequate and will show a dehiscence when a 4-mm diameter implant is placed ${ }^{2}$. Thus, an augmentation of the existing alveolar bone is necessary for the placement of the implant in a favorable prosthetic position ${ }^{4}$. 
A variety of prosthetically-driven bone augmentation techniques for the deficient alveolar bone have been proposed in the literature. The more frequently reported techniques were: (1) guided bone regeneration (GBR)/using particulate bone grafting5; (2) onlay (veneer) block bone grafting with intraoral donor sites, such as chin, ramus, posterior mandible, and maxillary tuberosity ${ }^{6}$. (3) alveolar distraction osteogenesis ${ }^{7}$, and (4) ridge split ${ }^{8}$.

In 2000, Vercellotti ${ }^{9}$ introduced piezosurgery in the treatment of the atrophic jaw. Piezosurgery made split technique easier, safer and also reduced the risk of complications in the treatment of extreme atrophic crests. Moreover, the use of Piezosurgery has made the success of alveolar ridge split technique less dependent on the surgeon's skills and less affected by the type of procedure chosen ${ }^{10}$.

Favorable conditions of posterior mandible for ridge splitting techniques include long edentulous span, abundant bone height superior to the mandibular canal $(>12 \mathrm{~mm})$ and presence of cancellous bone between the dense outer cortical plates $^{11}$.

The disadvantage of this procedure is that if the complication arises and bone loss occurs, the patient is left with a larger bone defect than before. If favorable conditions are not present, clinician might prefer bone augmentation. Therefore, appropriate case selection and surgical technique is of great importance when considering the application of this technique ${ }^{11}$.

Drilling methods for endosteal implant placement comprises the subtractive bone activity of the drills performed under the assumption that bone particles would be drilled out so the device may be properly inserted in place. Recently, a drilling concept has been introduced for the placement of endosteal implants through an osseodensification drilling ${ }^{12,13}$.

Osseodensification (OD), a non-extraction technique, was developed by Huwais ${ }^{13}$ in 2013 and made possible with specially designed burs to increase bone density as they expand an osteotomy ${ }^{12}$.

Unlike traditional bone drilling technologies, osseodensification does not excavate bone tissue. Rather, it preserves bone bulk, so bone tissue is simultaneously compacted and autografted in an outwardly expanding direction to form the osteotomy. It is accomplished by using proprietary densifying burs. When the densifying bur is rotated at high speed in a reversed, non-cutting direction with steady external irrigation (Densifying Mode), a dense compacted layer of bone tissue is formed along the walls and base of the osteotomy ${ }^{14,15}$.

Primary implant stability is defined as the biomechanical stability upon implant insertion, being influenced by numerous factors, such as: bone quantity and quality, the geometric design of the implant, surgical technique, and insertion torque. From this stability, new bone develops around the surface of the implant, constituting a biological fixation named secondary implant stability ${ }^{16,17}$.

Clinically the implant stability may be assessed either by recording the insertion torque value or by the use of the resonance frequency analysis. Insertion torque measurement is a well-established method. However, it may assess only primary stability during implant placement. Resonance frequency analysis may be used at any time point during implant's life ${ }^{18}$.

The present study was designed to evaluate and compare between the piezosurgical ridge splitting and osseodensification in the implant primary stability.

\section{SUBJECTS AND METHODS}

This study was designed as a randomized, controlled clinical trial conducted on 7 patients with bilateral missing mandibular posterior teeth seeking for receiving dental implants. They were selected from the Outpatient Clinic of Oral Medicine, Peri- 
odontology, Oral diagnosis and radiology Department, Faculty of Dentistry, Al-Azhar University (Assiut branch).

\section{All subjects were}

1. Free from any systemic diseases.

2. Aged between 25 and 60 years with bilateral missing mandibular posterior teeth and alveolar bone volume of area planned to receive implant with $3-5 \mathrm{~mm}$ width labio-lingually and minimum of $10 \mathrm{~mm}$ height.

3. Non-smokers and cooperative.

4. Not already received or lost implants in the potential implantation site.

Randomized clinical study was conducted on 7 patients. A total of 28 implants were placed in the selected patients.

Split mouth technique was applied on each patient so one side treated by piezosurgery technique and other side treated by osseodensification technique (The selection of the technique of each patient side by coin flipping) and grouping was done as following:

Group I : 14 implant sites which received piezosurgery technique followed by implant placement.

Group II : 14 implant sites which received osseodensification technique followed by implant placement.

\section{Preoperative therapy}

Each case was evaluated through examination of $\mathrm{CBCT}$ and periapical radiographs to assess bone quality and quantity, to quantify the ridge height and width of the supporting bone, and to locate major anatomical features.

All patients were subjected to proper oral hygiene instructions, scaling and root planning for all teeth and periodontal treatment if needed to provide an oral environment more favorable to wound healing. Prophylactic antibiotic therapy one day before surgery and 5 days after surgery.

\section{Surgical intervention:}

The site of surgery was anesthetized with 1:100,000 epinephrine. Once anesthetized, crestal incision was done, and full thickness flap was reflected.

Using piezoelectric surgery unit (piezotome ${ }^{\circledR}$ solo, acteon, satelec, France), a horizontal crestal cut was produced along the crest of the bone. The cut depth extended through the cortical bone to reach the spongy bone. The depth of the horizontal cut was approximately $1 \mathrm{~mm}$ shorter than the overall length of the implant to be placed. Two vertical cuts were made and these were connected to the horizontal crestal cut (except in patients with long span ridge for which vertical cuts were not needed) then drilling at the target site of implant placement from pilot drill to the final drill according to the manufacture instructions in a length approximately $1 \mathrm{~mm}$ longer than the horizontal cut (fig. 1).

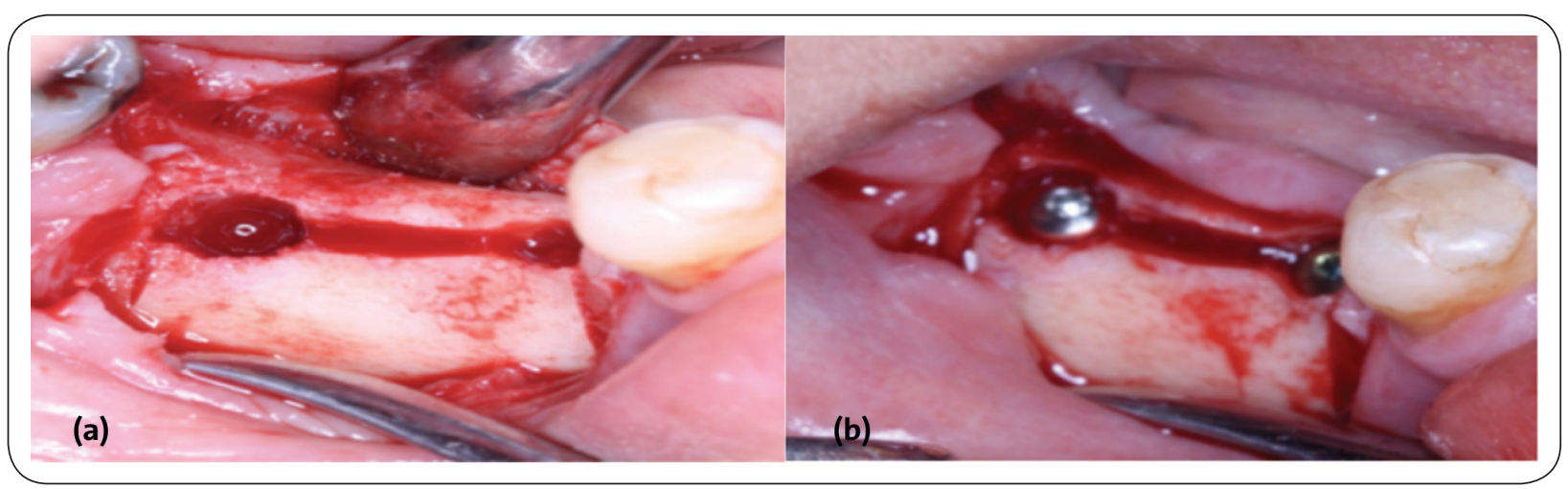

Fig. (1) (a,b) A clinical photographs of piezoelectric surgery unit, female 38 aged patient with piezosurgial ridge splitting and implant placement. 
The site preparation for implants in osseodensification began sites with site marking. Then, a 1.5$\mathrm{mm}$ initial pilot osteotomy was created with a pilot drill rotated at 1200 RPM in a clockwise rotation (CW) to the wanted depth utilizing a high speed surgical handpiece and a surgical Motor (surgic pro ${ }^{\circledR}$ NSK, Japan). Using paralleling pins, an X-ray was taken to confirm the angulation between the adjacent teeth and the implants.

Once the correct position of the implant was confirmed, osseodensification was utilized using Densah ${ }^{\circledR}$ Bur VT1525 2.0-mm (Versah, LLC, USA) running in a non-cutting counterclockwise (CCW) direction at 1200 RPM (Densifying Mode) with a bouncing motion to expand the osteotomy. Sequential use of Densah Bur running in a noncutting counterclockwise (CCW) direction at 1200 RPM (Densifying Mode) with a bouncing motion was utilized to expand the osteotomy to the wanted diameter Incremental drilling was done using progressively larger drill sizes. Sequence of bur sizes (diameter) used was based on the diameter of the proposed implant (fig. 2).

Insertion of the implant fixtures (Neobiotech ${ }^{\circledR}$ Neobiotech Co.,Ltd, korea) were achieved according to manufacture instructions. Careful screwing and seating of these tapered implants into the bone was performed until all exposed threads were submerged and the platform remained flush with the crestal bone with gaining primary stability of the implants and fixation in its position and implants were evaluated for primary stability.

-Cover screws were then fixed to the implants.

\section{Clinical evaluation}

\section{Implant primary stability:}

All implants were evaluated for primary stability once after implant insertion with an Osstell ${ }^{\circledR}$ Mentor magnetic resonance device (Osstell; Integration Diagnostics Ltd., Göteborg, Sweden) that uses resonance frequency analysis for determining implant stability. This method requires the placement of an electronic transducer on the implant head or prosthetic abutment with a retaining screw followed by the passing of a low voltage current through the transducer that was undetectable by the patient. Resistance to vibration of the transducer to the surrounding bone was registered in a small computer device, and these vibration measurements were recorded in units of hertz $(\mathrm{Hz})$. Hertz measurements were calibrated for each transducer and converted to implant stability quotient (ISQ) units using the device computer. ISQ values of 40 or less indicated that the implant was compromised with the potential for complications and lack of stability (fig. 3 a,b).

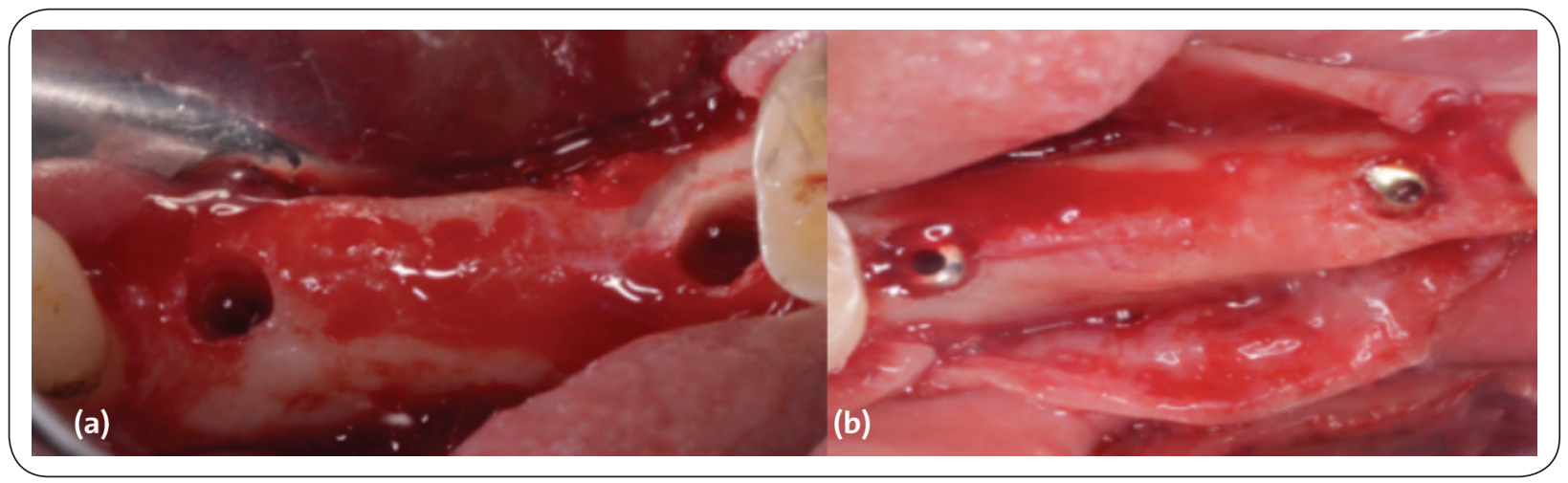

Fig. (2) (a,b) Aclinical photographs of Densah burs, female 38 aged patient with osseodensification drilling and implant placement. 


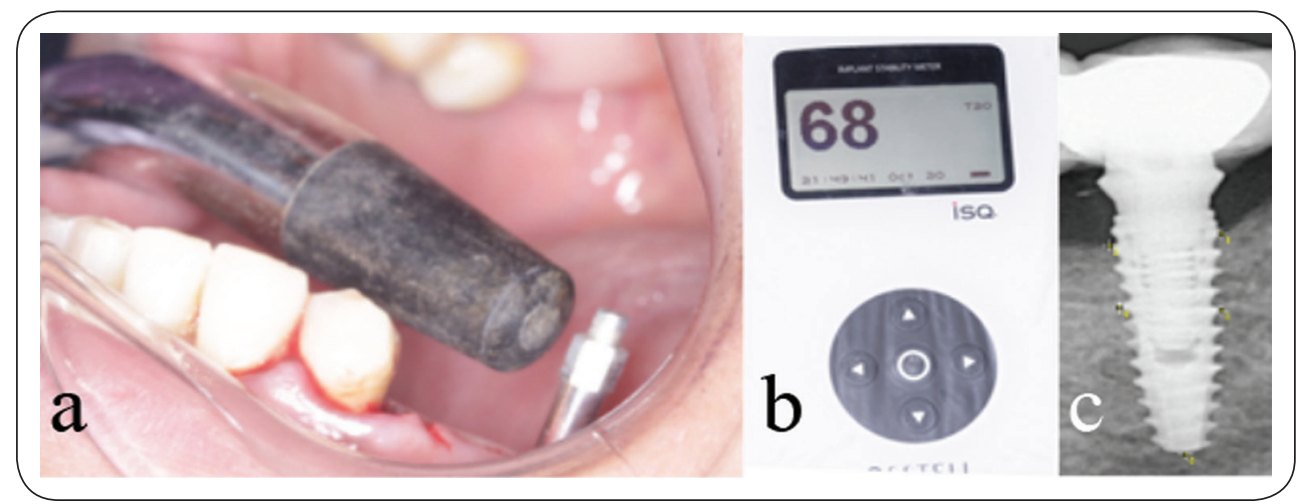

Fig. (3) (a,b)A clinical photographs of female 38 aged patient with measuring and the reading of osstell. (c) Three months radiograph of dental implant with bone density analysis.

\section{Bone density analysis:}

On each 3 months periapical radiograph, five standardized assessment areas of interest (AOI) were marked. Two areas were placed at most coronal peri -implant bone, one in the mesial and one on the distal peri-implant bone right next to the implant surface, two at half-length of the intraosseous part of the implant, the last AOI was placed on the periimplant bone right next the tip of the apex (fig. 3,c).

The analysis of the grey scale value ( $\triangle$ GSV) of the AOI was performed with ImageJ ${ }^{\circledR}$ (Vs. 1.46r, National Institutes of Health, USA).

\section{RESULTS}

The data was recorded, tabulated and statistically analyzed using paired sample t-test within each group, and unpaired t-test for comparing the two groups The significance level was set at $\mathrm{p} \leq 0.05$. Statistical analysis was performed with SPSS software version 24 (SPSS Inc., Chicago, Il., USA)

\section{Osstell reading:}

- The mean value $\pm \mathrm{SD}$ on Ostell reading in the two groups illustrated in table (1).

- Unpaired t-test for comparing means, standard deviation, t-values and p-values among the two groups illustrated in table (1) representing moderate statistical significant difference in group II when compared with group I.

\begin{tabular}{|c|c|c|c|c|}
\hline & \multicolumn{2}{|c|}{ Osstell reading } & \multicolumn{2}{|c|}{ Bone density analysis } \\
\hline & Mean & SD & Mean & SD \\
\hline Group I & 62.80 & 2.25 & 115.22 & 3.86 \\
\hline Group II & 68.30 & 3.83 & 131.98 & 5.30 \\
\hline \multicolumn{5}{|c|}{ Unpaired $\mathrm{t}$-test Group II vs. group I } \\
\hline $\mathrm{T}$ & \multicolumn{2}{|c|}{$\mathrm{p}$} & $\mathrm{T}$ & $\mathrm{P}$ \\
\hline 4.398 & \multicolumn{2}{|c|}{$0.001 * *$} & 8.079 & $0.001 * *$ \\
\hline
\end{tabular}

*Statistically significant: $(p<0.05)$

**: High statistically significant: $(p<0.01)$

\section{DISCUSSION}

Dental rehabilitation of horizontally deficient alveolar crests by osseointegrated implants can be challenging. Strategies such as host-derived block autografts to membrane-guided tissue regeneration have all been established as a predictable surgical therapy to augment bone volume prior to implant placement ${ }^{19}$. However, the augmentation of bone precedes dental implant surgery with an additional surgery for grafting and bone healing, adding additional time and costs to complete the treatment ${ }^{20}$.

Our study selected posterior mandibular region as a target area that agreed with Emami E. et al. ${ }^{21}$ who cleared that bone loss is an ongoing process 
following tooth loss affecting the mandible four times more than the maxilla.

This study was done by split-mouth design that agreed with studies by Lesaffre et al. ${ }^{22}$, who realized that split-mouth design is very successful design in many oral health researchers. The attractiveness of the split-mouth design is the removal of much of the inter-subject variability thereby increasing the power of the study compared to the whole-mouth design.

The width of the ridge in our study was 3-5 $\mathrm{mm}$. that concur with Scipioni A. et al. ${ }^{23}$ who discussed that when the bucco-lingual bone width is $3 \mathrm{~mm}$ or greater but $<6 \mathrm{~mm}$, to allow implant placement, augmentation of the alveolar ridge using a ridge splitting and bone expansion technique is a viable option. The $3 \mathrm{~mm}$ of bone should have at least $1 \mathrm{~mm}$ of trabecular bone sandwiched between the cortical plates. That will ensure $1.5 \mathrm{~mm}$ of bone (cortical and cancellous) on either side of the split ridge and allow the bone to spread and maintain a good blood supply. Several ridge split techniques have been developed in past few decades and includes split crest osteotomy ${ }^{9,23}$, Ridge expansion osteotomy and numerous modifications on $\mathrm{it}^{24}$.

This study in agreement with Blus et al. ${ }^{25}$, that using the ultrasonic bone surgery (piezosurgery) to split the ridge crest and insert implant immediate in mandible.

The gap was left to be filled with a blood clot giving the opportunity for normal wound healing resembling an extraction socket. That agreed with Abu Tair J A ${ }^{26}$ who depended upon the fact that fresh extraction sockets in these areas are always wider than $5 \mathrm{~mm}$ and they heal by secondary intension without the need for bone grafting or using guided regeneration techniques.

In the current study, the alveolar ridge split technique with simultaneous implant placement is performed to shorten the total treatment time and to eliminate second surgical procedure morbidity as Sohn D S et al. ${ }^{27}$ discussed in his study. However, he cleared that there is a higher risk of malfracture of the osteotomized bone segments, especially in the mandible, a lack of initial stability for the implants, and a compromised implant placement in the buccolingual and apicocoronal direction.

Osseodensification (OD) is a newer technique of preparation of the implant bed, to develop a condensed autograft surrounding the implant, which enhances implant stability which was developed by Huwais $\mathrm{S}^{12,13}$.

In vitro testing reported that the densah burs allow bone preservation and condensation through compaction autografting during osteotomy preparation, increasing the peri-implant bone density (BV\%), and the implant mechanical stability ${ }^{15}$.

Mentioning the contraindications, OD does not work with cortical bone as cortical bone is a nondynamic tissue which lacks plasticity. Densification of xenografts should be avoided because they behave biomechanically different than the bone tissue, as they have only inorganic content and they just provide the bulk without any viscoelasticity ${ }^{28}$.

Primary stability is the mechanical anchorage of a biocompatible implant as it is wedged in a properly prepared hole in the living bone. Primarily this contact between the two materials has only mechanical connection characteristics and not biological. However, bone is a living tissue and, due to surgical trauma, a periphery of about $1 \mathrm{~mm}$ around the implant body is devitalized, resorbed and remodeled ${ }^{29,30}$.

We found in this study that there was moderate statistically significant difference in ISQ reading and bone density between the two groups in favor of osseodensification group that through with Lahen $\mathrm{B}$ et al. ${ }^{31}$, which in their study examined the effect of OD on the primary stability and early osseointegration of implants. Their results showed that the OD drilling technique significantly enhanced Insertion torque values which are considered in this study as a method to gauge device primary stability. After six weeks in vivo, histometric results suggest that the experimental groups drill design positively influenced osseointegration. Thus they concluded 
that regardless of the design of implant, the OD drilling technique enhanced the primary stability and BIC bone-to-implant contact. They also concluded it as a result of densification of autologous bone debris at the bone walls. Also a study conducted by Huwais $\mathrm{S}$ and Meyer $\mathrm{EG}^{15}$ demonstrated that OD increase the bone mineral density around periphery of the osteotomy and produces a compaction autografted bone along the entire depth of the osteotomy, furthermore, due to the spring back effect created by the elastic strain recovery of the compacted bone, a reverse compression of the bone tissue against the implant body is created and so enhance the implant primary stability.

Stavropoulos et al. ${ }^{32}$ reported good primary stability of implants placed with bone condensation technique, despite the minor cracks detected in the coronal portion of the alveolar ridge. Nevins et al. ${ }^{33}$ compared low, moderate and high condensation of the walls of the implant bed. The scenario intended to induce moderate degree of compression provided the best overall results.

In other studies, comparison of drill and piezosurgical osteotomies revealed greater ISQ values, limited decrease in ISQ values, and an earlier shifting from a decreasing to an increasing stability pattern and high comparable survival rates in favor of piezosurgery ${ }^{34,35}$.

\section{CONCLUSIONS}

1. Both piezosurgical ridge splitting and osseodensification were shown to be effective in increasing narrow ridge width.

2. The osseodensification technique was demonstrated to be able to increase peri-implant bone density and so implant primary stability of the dental implants with avoiding bone sacrifice.

3 . Future studies will focus on expanding the sample size as well as the timeline of the study to allow investigation of long-term prognosis of these techniques.

\section{REFERENCES}

1. Santagata M, Guariniello L, D'Andrea A, Tartaro G. A modified crestal ridge expansion technique for immediate placement of implants: a report of three cases. J Oral Implantol 2008;34(6):319-324.

2. Laster Z, Rachmiel A, Jensen OT. Alveolar width distraction osteogenesis for early implant placement. J Oral Maxillofac Surg 2005;63(12):1724-1730.

3. Iasella JM, Greenwell H, Miller RL, Hill M, Drisko C, Bohra AA. Ridge preservation with freeze-dried bone allograft and a collagen membrane compared to extraction alone for implant site development: a clinical and histologic study in humans. J Periodontol 2003;74:990-999.

4. Aimetti M, Romano F, Griga FB, Godio L. Clinical and histologic healing of human extraction sockets filled with calcium sulfate. Int J Oral Maxillofac Impl 2009;24:902-909.

5. Chiapasco M, Zaniboni M, Boisco M. Augmentation procedures for the rehabilitation of deficient edentulous ridges with oral implants. Clin Oral Implants Res 2006; 2(10):136-159.

6. Annibali S, Bignozzi I, Sammartino G, La Monaca G, Cristalli MP. Horizontal and vertical ridge augmentation in localized alveolar deficient sites: a retrospective case series. Implant Dent 2012; 21:175-185.

7. Kempton SJ, McCarthy JE, Afifi AM. A systematic review of distraction osteogenesis in hand surgery: What are the benefits, complication rates, and duration of treatment? Plast.Reconstr.Surg. 2014;133:1120-1130.

8. Chiang T, Roca AL, Rostkowski S, Drew HJ, Simon B. Reconstruction of the narrow ridge using combined ridge split and guided bone regeneration with rhPDGFBB growth factor enhanced allograft. Int J Periodontics Restorative Dent 2014;34:123-130.

9. Vercellotti T. Technological characteristics and clinical indications of piezoelectric bone surgery. Minerva Stomatol. 2004;53(5):207-14

10. Vercellotti T, De Paoli S., Nevins M. "The piezoelectric bony window osteotomy and sinus membrane elevation: introduction of a new technique for simplification of the sinus augmentation procedure," Int J Periodontics Restorative Dent 2001;21(6):561-567.

11. Misch CM. Implant site development using ridge splitting techniques. Oral Maxillofac Surg Clin North Am 2004;16(1):65-74. 
12. Huwais S. Autografting Osteotome. World Intellectual Property Organization Publication, Geneva, Switzerland 2014.

13. Huwais S. inventor; Fluted osteotome and surgical method for use. US Patent Application US2013/0004918. January 3, 2013.

14. EG, Huwais S. Osseodensification Is A Novel Implant Preparation Technique That Increases Implant Primary Stability By Compaction and Auto-Grafting Bone. American Academy of Periodontology. [abstract]. San Francisco, CA. 2014.

15. Huwais S, Meyer EG. Osseodensification: A novel approach in implant preparation to increase primary stability, bone mineral density and bone to implant contact. Int J Oral Maxillofac Implants 2017;32(1):27-36.

16. Papadpyridakos P, Chen CJ, Singh M, Weber HP, Gallucci GO. Success Criteria in implant dentistry: A systematic review. J Dent Res. 2012;91:242-248.

17. Gómez-Polo M, Ortega R, Gómez-Polo C, Martín C, Celemín A, Del Río J. Does lenght, diameter, or bone quality affect primary and secondary stability in selftapping dental implants?. J Oral Maxillofac Surg. 2016;74:1344-1353.

18. Trisi P, Perfetti G, Baldoni E, Berardi D, Colagiovanni M, Scogna G. Implant micromotion is related to peak insertion torque and bone density. Clin Oral Implants Res, 2009;20:467-471.

19. Elgali I, Omar O, Dahlin C. Guided bone regeneration: materials and biological mechanisms revisited. Eur J Oral Sci 2017;125:315-337.

20. Sanz-Sanchez I, Ortiz-Vigon A, Sanz-Martin I. Effectiveness of lateral bone augmentation on the alveolar crest dimension: a systematic review and meta-analysis. J Dent Res 2015;94:128-142.

21. Emami E, De Souza RF, Kabawat M, Feine JS. The impact of edentulism on oral and general health. Int J Dent 2013.

22. Lesaffre E, Garcia Zattera MJ, Redmond C, Needleman I. Reported methodological quality of split-mouth studies. J Clin Periodontol 2007; 34(9):756-761.

23. Scipioni A, Bruschi GB, Calesini G. The edentulous ridge expansion technique: a five-year study. Int J Periodontics Restorative Dent 1994;14:451-459

24. Summers RB. The osteotome technique: Part 2 - The ridge expansion osteotomy (REO) procedure. Compendium. 1994;15:422-426.
25. Blus C, Szmukler-Moncler S, Vozza I, Rispoli L, Polastri C. Split-crest and immediate implant placement with ultrasonic bone surgery (piezosurgery): 3-year follow-up of 180 treated implant sites. Quintessence Int 2010;41(6):463-469.

26. Abu Tair JA. Modification of mandibular ridge splitting technique for horizontal augmentation of atrophic ridges. Ann Maxillofac Surg 2014;4(1):19-23.

27. Sohn D S, Lee H J, Heo J U, Moon J W, Park I S, Romanos G E. Immediate and delayed lateral ridge expansion technique in the atrophic posterior mandibular ridge. J. Oral Maxillofac. Surg. 2010;68(9):2283-2290.

28. Hema Kanathila and Ashwin Pangi. An Insight Into the Concept of Osseodensification J Clin Diagn Res . 2018;12(7):1-3.

29. Marković A, Calasan D, Colić S, Stojčev-Stajčić L, Janjić B, Mišić T. Implant stability in posterior maxilla: bonecondensing versus bone-drilling: a clinical study. Oral Surg Oral Med Oral Pathol Oral Radiol Endod 2011;112:557-563.

30. Buchter A, Kleinheinz J, Wiesmann HP, Kersken J, Nienkemper M, Weyhrother HV. Biological and biomechanical evaluation of bone remodelling and implant stability after using an osteotome technique. Clin Oral Implants Res 2005;16:1-8.

31. Lahens B, Neiva R, Tovar N, Alifarag AM, Jimbo R, Bonfante EA. Biomechanical and histologic basis of osseodensification drilling for endosteal implant placement in low density bone. An experimental study in sheep. J Mech Behav Biomed Mater 2016;63:56-65.

32. Stavropoulos A, Nyengaard JR, Lang NP, Karring T. Immediate loading of single SLA implants: drilling vs. osteotomes for the preparation of the implant site. Clin Oral Implants Res 2008;19:55-65.

33. Nevins M, Nevins ML, Schupbach P, Fiorellini J, Lin Z, Kim DM. The impact of bone compression on bonetoimplant contact of an osseointegrated implant: a canine study. Int J Periodontics Restorative Dent 2012;32:637-645.

34. Stelzle F, Neukam FW, Nkenke E. Load dependent heat development, thermal effects, duration and soft tissue preservation in piezosurgical implant site preparation: an experimental ex vivo study. Int J Oral Maxillofac Implants 2012;27:513-522.

35. Vercellotti, T., Stacchi, C., Russo, C., Rebaudi, A., Vincenzi, G. et al. Ultrasonic implant site preparation using piezosurgery: a multicenter case series study analyzing. Int J Periodontics Restorative Dent. 2014;34:11-18. 


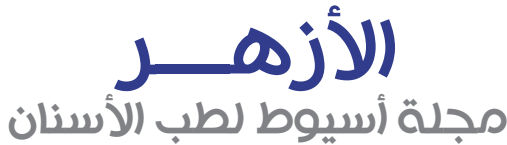

النشر الرسمي لكلية طب الأسنان

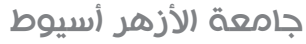

الملخص العربي

الغرض من الدراسة

أجريت هذه الدراسـة لتقييه والمقارنة ما بين فاعلية شـق الحافة بالموجات فوق الصوتية و التكثيف العظهي في الثبات الاولى للغرسات بغرض

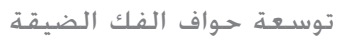
الموضوعات والأساليب: تم تقسيم الجزء الخلفي من الفك السفلي للمرضى إلى مجموعتين: الججموعة الأولى: أربعة عشر موقعا للغرسـات السـنية تم فيه التوسعة باستخـدام شق الحـافة بالموجات فوق الصوتية. الجمهوعة الثانية: أربعة عشـر موقعا للغرسـات السـية تم فيه التوسعة باستخدام التكثيف العظمى. الخطوات المستخدمة تم التقييم الاكلينيكي للثبات الأولي للغرسـة السنية بعد إجراء الزرع مباشـرة.- تم التقييم الشعاعي بتحليل كثافة العظام حول الغرسات بعد الشهر الثالث.

النتائج

قياس الثبات الأولي للغرسـة: هناك فروق إحصائية متوسطة ما بين الجمهوعتين لصالح الجمموعة الثانية. ثليل كثافة العظام حول الغرسات:

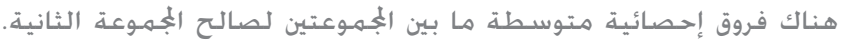

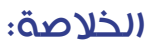

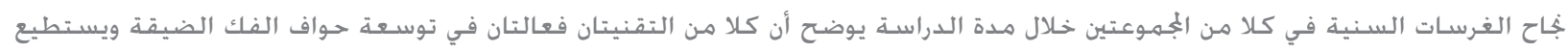

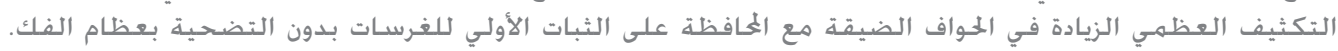

